\title{
Adipokines, Metabolic Syndrome and Rheumatic Diseases
}

\author{
Vanessa Abella, ${ }^{1,2}$ Morena Scotece, ${ }^{1}$ Javier Conde, ${ }^{1}$ Verónica López, ${ }^{1}$ Verónica Lazzaro, ${ }^{1,3}$ \\ Jesús Pino, ${ }^{4}$ Juan J. Gómez-Reino, ${ }^{1}$ and Oreste Gualillo ${ }^{1}$ \\ ${ }^{1}$ SERGAS, Research Laboratory 9, NEIRID Lab (Neuroendocrine Interactions in Rheumatology and Inflammatory Diseases), \\ Institute of Medical Research (IDIS), Santiago University Clinical Hospital, 15706 Santiago de Compostela, Spain \\ ${ }^{2}$ Department of Molecular and Cellular Biology, University of Coruña (UDC), 15071 A Coruña, Spain \\ ${ }^{3}$ University Magna Graecia of Catanzaro, 88100 Catanzaro, Italy \\ ${ }^{4}$ SERGAS, Division of Orthopaedics Surgery and Traumatology, Santiago University Clinical Hospital, \\ 15706 Santiago de Compostela, Spain
}

Correspondence should be addressed to Oreste Gualillo; oreste.gualillo@sergas.es

Received 10 December 2013; Revised 10 January 2014; Accepted 10 January 2014; Published 26 February 2014

Academic Editor: K. Blaser

Copyright (C) 2014 Vanessa Abella et al. This is an open access article distributed under the Creative Commons Attribution License, which permits unrestricted use, distribution, and reproduction in any medium, provided the original work is properly cited.

\begin{abstract}
The metabolic syndrome (MetS) is a cluster of cardiometabolic disorders that result from the increasing prevalence of obesity. The major components of MetS include insulin resistance, central obesity, dyslipidemia, and hypertension. MetS identifies the central obesity with increased risk for cardiovascular diseases (CVDs) and type-2 diabetes mellitus (T2DM). Patients with rheumatic diseases, such as rheumatoid arthritis, osteoarthritis, systemic lupus erythematosus, and ankylosing spondylitis, have increased prevalence of CVDs. Moreover, CVD risk is increased when obesity is present in these patients. However, traditional cardiovascular risk factors do not completely explain the enhanced cardiovascular risk in this population. Thus, MetS and the altered secretion patterns of proinflammatory adipokines present in obesity could be the link between CVDs and rheumatic diseases. Furthermore, adipokines have been linked to the pathogenesis of MetS and its comorbidities through their effects on vascular function and inflammation. In the present paper, we review recent evidence of the role played by adipokines in the modulation of MetS in the general population, and in patients with rheumatic diseases.
\end{abstract}

\section{Introduction}

The metabolic syndrome (MetS) is a cluster of cardiometabolic disorders that result from the increasing prevalence of obesity. The major components of MetS include insulin resistance, central obesity, dyslipidemia, and hypertension [1]. It is widely accepted that the concept of MetS identifies the central obesity with increased risk for cardiovascular diseases (CVDs) and type-2 diabetes mellitus (T2DM) [2,3]. Nevertheless, it still lacks a universally accepted definition. Various diagnostic criteria have been proposed by different organizations over the past decade, thus giving five definitions for MetS [4-8]. Recently, the International Diabetes Federation (IDF) and the American Heart Association/National Heart, Lung, and Blood Institute (AHA/NHLBI) have developed one unified definition [9]. Several rheumatic diseases (rheumatoid arthritis (RA), osteoarthritis (OA), systemic lupus erythematosus (SLE), and ankylosing spondylitis (AS)) have been associated with an increase in the prevalence of CVDs. Though traditional cardiovascular risk factors (sex, smoking, dyslipidemia, age, and hypertension) have been involved in the pathogenesis of CVDs in patients with rheumatic diseases, these features do not completely explain the enhanced cardiovascular risk in this population [10]. For instance, CVDs are responsible for almost $50 \%$ excess of mortality in patients with RA [11, 12]. Furthermore, the incidence of CVDs is increased when obesity is present in patients with rheumatic disorders. Evidence now indicates that MetS begins with excess of central adiposity [13]. Thus, MetS and obesity, in particular, pathologic dysfunction of fat mass, due to altered secretion patterns of proinflammatory adipokines, could be the link between CVDs and rheumatic diseases [14, 15]. Adipose tissue is now recognized as an endocrine organ able to secrete adipose-derived factors named adipokines. 
Adipokines have been linked to the pathogenesis of MetS and its comorbidities through their effects on vascular function and inflammation $[14,16,17]$. The present paper reviews recent lines of evidence of the role played by adipokines produced by adipose tissue in the modulation of MetS in the general population and in patients with rheumatic diseases.

\section{Metabolic Syndrome and Rheumatic Diseases}

Patients with chronic rheumatic diseases have an increased risk for CVDs morbidity and mortality but the pathogenetic factors involved are not yet fully understood. MetS may provide an additional link between accelerated atherosclerosis and inflammation in these diseases [2] (Figure 1).

The great majority of these studies demonstrated that the prevalence of MetS is higher in rheumatological diseases than in the control populations, suggesting that either the presence or the treatment of those diseases seems to influence the risk of developing metabolic syndrome [18]. MetS is not uncommon in patients with RA [19]. The risk of having moderate-to-severe RA was higher in patients with MetS than in those without MetS, and the disease activity correlated with the number of MetS parameters present. Thus, MetS might have inflammatory milieu leading to the occurrence of more severe RA [20]. In studies evaluating the association of MetS and RA, the prevalence of MetS is higher in RA subjects, but the values vary according to the MetS criteria used [21, 22]. A different approach was developed by Crowson et al. The authors noticed that a more clinically relevant question was whether the prevalence of MetS is increased in RA subjects without overt CVD. In fact, they observed higher prevalence of MetS in RA subjects (33\%) compared with non-RA subjects (25\%) [23].

The increase of fat mass is also related to the occurrence of $\mathrm{OA}$ and to the plethora of cardiovascular comorbidities. Regarding the influence of fat mass on OA, it is evident that biomechanical aspects are of weight in the pathogenesis of diseases. Biomechanical loading is necessary for the maintenance of cartilage homeostasis. However, abnormal loading is associated with inflammatory and metabolic imbalances, in part because it triggers the same signaling pathways as those induced by inflammatory cytokines [24]. Chondrocytes sense mechanical stress through ion channels, integrin-mediated connections to the extracellular matrix, and intracellular or membrane deformation [25]. However, OA is more common in women $[26,27]$ and exists in non-weight-bearing joints [28], indicating that a metabolic component is also present [29]. Of late, OA and MetS have been related to each other. The prevalence of MetS is higher in OA subjects [30, 31]. Recently, Zhuo et al. proposed a theory focused on inflammation, oxidative stress, common metabolites, and endothelial dysfunction to link metabolic OA aetiologically to MetS. They suggest that metabolic OA should be a new facet of the definition of MetS, supported by its strong associations and shared mechanisms with MetS components. However, further research is needed to define the reciprocal influence of OA on the currently accepted components of MetS [32].
A link between SLE and MetS also exists. Most of the reports showed major prevalence of MetS in lupus patients than in healthy controls. MetS is also common in young patients with recently diagnosed SLE [33]. Moreover, subjects with SLE and MetS presented higher levels of inflammatory markers than SLE without MetS [34-36]. SLE patients also have a higher risk of experiencing CVDs and metabolic disorders related to MetS may contribute to overall CVD risk [37].

The link between MetS and rheumatic diseases is also at play in AS. It has been reported that AS patients have risk of experiencing MetS and CVDs than in healthy controls $(45.8 \%$ versus 10.5\%) [38], even after receiving anti-tumor necrosis factor (anti-TNF) therapy [39]. Moreover, in these patients, MetS was associated with higher disease activity.

Several features of MetS, such as dyslipidemia, have also been reported, with higher prevalence in Sjögren's syndrome. It is noteworthy that metabolic alterations were associated with a differentiated pattern of clinical and immunological Sjögren's syndrome expression but not with Sjögren's syndrome-related therapies (except for the higher frequency of T2DM observed in patients treated with corticosteroids) [40].

\section{Adipokines and Metabolic Syndrome}

White adipose tissue (WAT) is described as an endocrine organ, which secretes a wide variety of factors called adipokines. Adipokines are pleiotropic molecules that contribute to the so-called low-grade inflammatory state of obese subjects creating a cluster of metabolic aberrations including autoimmune and inflammatory diseases that affect joints and bone [41, 42]. Recent studies show a potential source of adipokines at articular level: the infrapatellar fat pad (IPFP). Actually, recent evidence indicates an inflammatory phenotype of this adipose compartment in patients with OA showing that IPFP could contribute to the pathophysiological changes in the OA joint via the local production of cytokines and adipokines [43]. In the majority of obese patients, a dysfunctional adipose tissue mechanistically links obesity to other manifestations such as CVDs and MetS. This dysfunction is caused by complex disequilibrium between genetic and environmental factors, which is characterized by adipocyte hypertrophy, hypoxia, and inflammation. The direct consequence of this dysfunction is that adipokine secretion is shifted to an atherogenic, diabetogenic, and proinflammatory secretion pattern. According to the recent literature, all known adipokines are markedly dysregulated when abnormal abdominal fat accumulation is present, thereby promoting metabolic and cardiovascular disorders (Figure 1). Adipokines were recently proposed as novel biomarkers and regulators of MetS, given the association of adipokines plasma concentration and MetS [44]. Among the different adipokines, leptin and adiponectin were identified as relevant factors involved in interactions between metabolism and rheumatic disorders. Recent research suggests that leptin may be an important factor linking obesity, the metabolic syndrome, and cardiovascular disorders [45]. Additionally, 


\begin{tabular}{|c|c|c|c|}
\hline \multicolumn{4}{|c|}{ Cardiovascular diseases } \\
\hline $\begin{array}{l}\text { - Proatherogenic actions } \\
\text { - Causes endothelial } \\
\text { dysfunction } \\
\text { - Increases cardiomyocyte } \\
\text { apoptosis }\end{array}$ & $\begin{array}{l}\text { - Antiatherosclerotic effects: } \\
\text { inhibits ICAM-1, VCAM-1, a } \\
\text { E-selection. } \\
\text { - Cardioprotective effects: } \\
\text { suppression of apoptosis, } \\
\text { ROS production, and } \\
\text { inflammation }\end{array}$ & $\begin{array}{l}\text { - Correlates with } \\
\text { atherosclerotic plaque } \\
\text { instability } \\
\text { - Increases ICAM-1, } \\
\text { VCAM-1, and E-selectin }\end{array}$ & $\begin{array}{l}\text { - Contributes to } \\
\text { atherogenesis } \\
\text { - Increases endothelial } \\
\text { permeability }\end{array}$ \\
\hline Leptin & Adiponectin & Visfatin & Resistin \\
\hline $\begin{array}{l}\text { - Levels } \uparrow \text { or }(-) \\
\text { - Induces regulatory T-cells } \\
\text { energy and T-cell } \\
\text { receptor } \\
\text { hyporesponsiveness } \\
\text { - Anti-TNF- } \alpha \text { treatment } \\
\text { does not affect serum } \\
\text { leptin levels }\end{array}$ & $\begin{array}{l}\text { - Levels } \uparrow \\
\text { - Induces PGE2, IL-6, } \\
\text { IL-8, MMP-1, and MMP-13 } \\
\text { in synovial fibroblasts } \\
\text { - Induces iNOS, } \\
\text { IL-6, IL-8, and MMP-3 } \\
\text { in chondrocytes }\end{array}$ & $\begin{array}{l}\text { - Levels } \uparrow \\
\text { - Induces IL-6, IL-8, } \\
\text { and MMPs in synovial } \\
\text { fibroblasts }\end{array}$ & $\begin{array}{l}\text { - Levels } \uparrow \\
\text { - Induces TNF- } \alpha \text { and } \\
\text { IL-6 in synoviocytes } \\
\text { - Anti-TNF- } \alpha \text { decreases } \\
\text { serum resistin levels }\end{array}$ \\
\hline
\end{tabular}

FIGURE 1: Schematic representation of the relations between adipokines, cardiovascular diseases, and rheumatoid arthritis.

several clinical observations support an association between adiponectin levels and obesity-related metabolic dysfunction [46]. Given the recent pieces of evidence about the influence of adipokines in both metabolic disorders and rheumatic diseases, here we present an update summary of the main fat mass induced adipokines as key players in MetS and the most relevant rheumatic diseases.

\section{Leptin}

Leptin is a $16 \mathrm{kDa}$ nonglycosylated hormone that belongs to the class 1 cytokine superfamily. It is encoded by the obese $(o b)$ gene, the murine homolog of human LEP gene [47]. Leptin exerts its biological actions through the activation of $\mathrm{OB}-\mathrm{Rb}$ long-form isoform receptors encoded by the diabetes $(d b)$ gene. It is mainly produced by adipocytes, and its circulating levels positively correlate with WAT mass and body mass index (BMI). Leptin levels are mostly dependent on the amount of body fat, but its synthesis is also regulated by inflammatory mediators [48]. It decreases food intake and increases energy consumption by acting on specific hypothalamic nuclei, inducing anorexigenic factors and suppressing orexigenic neuropeptides [49].

4.1. Leptin and Metabolic Syndrome. Leptin was associated with MetS. Subjects with MetS had higher leptin levels compared with individuals without MetS. Furthermore, leptin was strongly correlated with waist circumference and insulin sensitivity [50]. Quercioli et al. observed that the decrease in leptin plasma levels with decreasing body weight was not observed to be related to the improvement in coronary circulatory function [51]. This observation may emphasize that beneficial effect of leptin plasma levels on endotheliumrelated coronary function may operate predominantly in morbidly obese individuals with a sevenfold increase of its concentration to counterbalance the adverse effects of obesity on coronary circulatory dysfunction as they are previously described [52]. Noteworthy, leptin levels predict MetS development independent of obesity. This association is specifically related to the development of glucose intolerance and insulin resistance [53]. Recent works support this relationship. Chiu et al. have observed how leptin concentrations varied in relation to MetS score in both genders in Taiwanese adults [54]. In another study, leptin showed significant positive correlation with parameters of insulin resistance and with triglycerides and strong negative correlation with HDL-cholesterol [55]. Insulin resistance and changes in lipid parameters are typical for early signs of MetS. Kontunen et al. assessed leptin levels in patients with arthritis and MetS. Their results showed higher leptin levels in subjects with arthritis and MetS than arthritis patients without MetS [56]. This suggests that leptin is associated with MetS but not directly with arthritis, although a marked increase in plasma levels of leptin in patients with RA was noted [57]. Leptin resistance is believed to be a major factor leading to MetS. The term leptin resistance is used to describe the failure of obesity-related hyperleptinemia to reduce food intake and increase energy expenditure, at which point MetS is present [58] (Figure 2).

4.2. Leptin and Rheumatic Diseases. Leptin has been associated with rheumatic diseases due to its ability to modulate bone and cartilage metabolism $[59,60]$. This adipokine plays main role in certain autoimmune diseases such as rheumatoid arthritis (RA). Generally, the present consensus is that leptin levels are elevated in patients with RA. However, in patients 


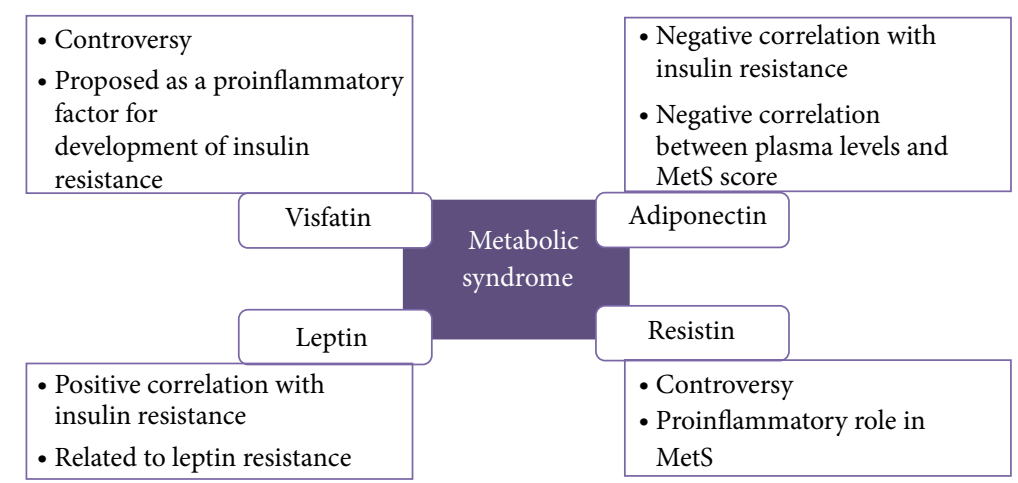

FIGURE 2: Schematic representation of adipokines actions in metabolic syndrome.

with RA undergoing anti-TNF- $\alpha$ therapy, no immediate change in serum leptin levels was observed [61] (Table 1). Several authors have also reported that the ratio between serum leptin levels and the synovial fluid (SF) is correlated with disease duration and parameters of RA activity [62]. Leptin has been supposed to play a part in RA although it is still unclear whether leptin can damage or protect joint structures in RA. In fact, this hormone, generally considered to be proinflammatory, has also been reported to be associated with reduced radiographic joint damage [63], and this effect could be related to anabolic effects of leptin [64]. The effects of leptin in RA are not only related to articular tissues. Leptin also modulates the activity of multiple immune cells [65]. The ability of leptin to induce regulatory T-cells anergy and T-cell receptor hyporesponsiveness has gained much interest since altered functioning of this cell type was described in RA [66].

Leptin has also been related to osteoarthritis $(\mathrm{OA})$ and cartilage metabolism. Recently, the NEIRID group showed that leptin expression was higher in infrapatellar fat pad (IPFP) and synovial tissues obtained from OA patients compared to healthy controls [43]. Furthermore, chondrocytes from human OA cartilage produce much more leptin than those from normal cartilage [64]. In fact, the expression pattern of leptin was related to the grade of cartilage destruction [64], with the highest levels of leptin in the advanced stages of the disease $[72,73]$. Leptin could perpetuate cartilage-degrading processes by inducing VCAM-1 expression, adhesion molecule responsible for leukocyte and monocyte infiltration at inflamed joints [74]. In addition, leptin induces IL-8 secretion in human primary chondrocytes contributing to the chemotactic gradient seen in inflamed joints [75]. Leptin is necessary for the development and progression of OA associated with obesity. Impaired leptin signalling associated with extreme obesity induces alterations in subchondral bone morphology but without increasing the incidence of OA [76]. These results suggest that obesity, per se, is not sufficient to induce OA.

The role of leptin in SLE is controversial. Nowadays, most of the studies suggest a role for leptin in this disease. Several authors found higher leptin levels in SLE patients compared with healthy controls, even after BMI correction $[36,77,78]$. Interestingly, in some of these studies, the hyperleptinemia was associated with CVDs and with several features of MetS
[36, 78]. On the other hand, other groups have described lower or unchanged circulating leptin levels in SLE patients compared to healthy control $[79,80]$.

The role of leptin in ankylosing spondylitis (AS) is still unclear and the data available are almost limited. For instance, certain studies have not found any correlation between serum leptin concentrations and markers of disease activity $[81,82]$. However, other authors determined an association among serum leptin levels, CRP, IL-6, and markers of disease activity [83, 84].

\section{Adiponectin}

Adiponectin is a 244-residue protein, also known as GBP28, apM1, Acrp30, or AdipoQ. It has structural homology with collagen VIII, collagen X, and complement factor Clq. Adiponectin acts via two receptors, one (AdipoR1) found predominantly in skeletal muscle and the other (AdipoR2) in liver. Transduction of the adiponectin signal by AdipoR1 and AdipoR2 involves the activation of AMPK, PPAR- $\alpha$, PPAR$\gamma$, and other signaling molecules. Adiponectin is mainly synthesized by adipose tissue in different molecular forms. Circulating adiponectin levels tend to be low in obese patients and increase with weight loss $[85,86]$. It increases fatty acid oxidation and glucose uptake in the muscle and reduces the synthesis of glucose in the liver. Ablation of the adiponectin gene has no dramatic effect in knockout mice on a normal diet, but when placed on a high fat/sucrose diet, they develop severe insulin resistance and exhibit lipid accumulation in muscles [85].

5.1. Adiponectin and Metabolic Syndrome. Unlike most other adipokines, plasma levels of adiponectin are decreased in obesity and related pathologies, including T2DM and CVDs [87-89]. Adiponectin levels are inversely proportional to obesity and insulin resistance, increasing with weight loss and with the use of insulin-sensitizing drugs [85]. Its secretion is inhibited by proinflammatory cytokines [90], suggesting that inflammation might be an important factor contributing to hypoadiponectinemia in insulin-resistant and obese states [91]. On the other hand, physical training increases circulating adiponectin and expression of its receptors [92]. 
TABLE 1: Major adipokines and the effect of anti-TNF- $\alpha$ therapy.

\begin{tabular}{lcccc}
\hline Adipokines & RA & Anti-TNF- $\alpha$ therapy & Reference \\
\hline Leptin & $\uparrow$ or $(-)$ & No effect in serum levels & {$[64]$} \\
Adiponectin & $\uparrow$ & No effect & {$[67]$} \\
Visfatin & $\uparrow$ & Reduction in serum levels & {$[68,69]$} \\
Resistin & $\uparrow$ & Not variation & {$[70]$} & {$[69,71]$} \\
\hline
\end{tabular}

Furthermore, dyslipidemia is also associated with low circulating levels of adiponectin, even in the absence of other MetS risk factors [93]. Recently, many studies have proposed adiponectin as a MetS biomarker. Bae et al. reported a strong negative correlation between MetS score and serum levels [94] (Figure 2). In subjects with nascent MetS (without confounding T2DM and/or CVDs), adiponectin concentration was lower than in controls [95]. Kim et al., in a prospective cohort study, stated that decreasing levels of adiponectin were progressively associated with increased incidence of MetS [96]. Of late, the serum/plasma leptin: adiponectin ratio ( $\mathrm{L}: \mathrm{A}$ ) has been reported to be associated with dyslipidemia and insulin resistance [97]. Kotani and Sakane suggested that the L:A ratio can serve as a clinically useful marker for detecting MetS characteristics in the general Japanese population [98]. From the historical cohort of the Brisighella Heart Study, Cicero et al. observed that subjects without MetS had significantly lower L: A ratio than those with MetS [99]. In other study, Kontunen et al. assessed adiponectin levels in patients with arthritis and MetS. Their results showed lower adiponectin levels in subjects with arthritis and MetS than arthritis patients without MetS [56]. Furthermore, GonzalezGay et al. suggested that low circulating adiponectin levels may be implicated in the development of CVD associated with RA. They observed that in patients with RA undergoing anti-TNF- $\alpha$ therapy, high-grade inflammation was independently and negatively correlated with circulating adiponectin concentrations. However, the interaction of high-grade inflammation with low circulating adiponectin concentrations was not likely to be TNF- $\alpha$ mediated in RA [100] (Table 1).

5.2. Adiponectin and Rheumatic Diseases. In contrast to its previously described protective role in CVDs and obesity, there are multiple lines of evidence that adiponectin acts as a proinflammatory factor in joints and it could be involved in matrix degradation. In cultured chondrocytes, adiponectin stimulates the secretion of proinflammatory mediators (iNOS, IL-6, and IL-8) [75, 101] and increases MMP-3 expression [102]. Adiponectin levels have been found to be higher in RA patients than in healthy controls $[57,63$, $67,103,104]$. Recently, it has been reported that adiponectin and adiponectin receptor-1 expression are higher in synovial fluids and the synovial tissues of RA patients compared with controls, confirming the correlation of circulating adiponectin levels with the severity of RA [67]. Recent studies showed that adiponectin might also contribute to synovitis and joint destruction in RA by stimulating MMP1 and MMP-13 [105]. Moreover, Frommer et al. described that the different isoforms of adiponectin can induce the expression of different genes involved in the pathogenesis of RA [106], further demonstrating that adiponectin could have detrimental effects on RA pathology.

Adiponectin is also implicated in the pathogenesis of OA. It has been reported that plasma and serum levels of adiponectin were significantly higher in OA patients than in healthy controls $[107,108]$ and correlate with disease severity [109]. In addition, adiponectin induces VCAM-1 expression [74] and IL-8 secretion [75] in human primary chondrocytes, contributing to, respectively, the leukocyte and monocyte infiltration and the chemotactic gradient seen in inflamed joints. However, some data analyzing the role of adiponectin in $\mathrm{OA}$ are controversial. Adiponectin has been shown to inhibit IL-1b-induced MMP-13 expression and to upregulate TIMP-2 production in chondrocytes [110]. Moreover, in STR/Ort mice, a spontaneous animal OA model, serum adiponectin levels were lower compared with the control group [111], suggesting a protective role for this adipokine in the development and/or progression of the disease. However, only a few clinical data support the hypothesis that adiponectin could be a protective molecule against OA. One study revealed an inverse correlation between adiponectin and disease severity [112]. Moreover, another recent study showed that serum adiponectin levels were not associated with radiographic hand OA severity [113]. These contradictory results can be explained by differences in patient characteristics and study protocols. It is also possible that the significance of adiponectin varies according to the phase and severity of the OA process.

Concerning the role of adiponectin in SLE, several studies have showed elevated levels of this adipokine in SLE patients $[77,79,114]$. Nevertheless, other authors did not find any difference in adiponectin levels between SLE patients and controls $[78,115]$. However, the same authors find increased MetS prevalence among subjects with SLE and low levels of adiponectin in SLE patients with insulin resistance (IR) compared to SLE subjects without IR, confirming the results by Sada et al. [77, 78]. It also has been reported that mice with experimental lupus, that lack adiponectin, develop more severe disease than wild-type mice, suggesting the involvement of adiponectin in regulating disease activity [116].

Little is known about the role of adiponectin in other rheumatic diseases, such as AS and Sjögren's syndrome. However, it has been reported that serum adiponectin levels are not different between AS patients and healthy controls 
[82]. Regarding Sjögren's syndrome, it has been described that adiponectin is expressed in salivary gland epithelial cells and this expression is higher in patients with Sjögren's syndrome [117].

\section{Visfatin}

Visfatin is a protein of approximately 471 amino acids and $52 \mathrm{kDa}$, also called PBEF (pre-B cell colony enhancing factor) and NAMPT (nicotinamide phosphoribosyltransferase) [118]. It was originally discovered in liver, bone marrow, and muscle, but it is also secreted by macrophages and visceral adipose tissue [119-121]. A specific receptor for visfatin has not been identified yet. It has been reported that visfatin is increased in obesity [122]. Moreover, leucocytes from obese patients produce higher amounts of visfatin compared with lean subjects [123]. It is supposed that visfatin has insulin mimetic properties; however, the role of this adipokine in glucose metabolism is still unclear and controversial [120]. Visfatin synthesis is regulated by factors such as glucocorticoids, TNF- $\alpha$, IL-6, and growth hormone (GH). Moreover, visfatin has been shown to induce chemotaxis and the production of IL- $1 \beta$, TNF- $\alpha$, and IL- 6 in lymphocytes from obese patients, suggesting potential involvement in the obesity-associated inflammatory state [122].

6.1. Visfatin and Metabolic Syndrome. The relation of visfatin with MetS is still confusing, but some studies have addressed this issue. Several authors have shown that serum visfatin was increased in subjects diagnosed with obesity, type-2 diabetes mellitus, and MetS [124]. However, other studies have not detected this relation. De Luis et al. reported that in a sample of 826 female obese subjects, $42.4 \%$ had MetS. Their findings showed that serum visfatin was correlated with total cholesterol and C-reactive protein. However, in the multivariate analysis, only C-reactive protein remained associated with serum visfatin and serum visfatin was not associated with the accumulation of MetS factors or the diagnosis of MetS [125]. Specifically, in obese women, Olszanecka-Glinianowicz et al. did not find a relation between visfatin levels and the presence of MetS. Nevertheless, these authors suggest that the proportion of the circulating visfatin and insulin molecules, expressed as the visfatin/insulin ratio, more than visfatin alone would be a good indicator for prevention of the development of insulin resistance and MetS in the obese [126]. In another approach, Bremer and Jialal investigated the levels of visfatin in plasma and in subcutaneous fat (SAT), finding no difference between MetS and control subjects [95]. Further studies are needed to analyse this unclear topic area, because visfatin could be a proinflammatory factor favoring the development of insulin resistance, as it was proposed [127] (Figure 2).

6.2. Visfatin and Rheumatic Diseases. Recent findings suggest, in arthritis animal models, that visfatin might act as a relevant regulator of the inflammation and joint destruction. In fact, it has been reported that serum and SF levels of visfatin were increased in arthritis models [128-130]. Clinical data also suggest a role for visfatin in the development of RA. The NEIRID group and others demonstrated that serum visfatin concentrations were higher in RA patients compared with healthy controls [57, 63, 131, 132]. Moreover, an association between serum visfatin levels and radiographic joint damage has been described $[63,133]$. By contrast, the relationship between visfatin and disease activity presents conflicting results. Although Alkady et al. reported an association between these two parameters [131], others did not find any correlation $[132,134]$. Results obtained from trials treating RA patients with anti-TNF- $\alpha$ therapy also present some discrepancies. Several authors described a reduction in visfatin levels upon anti-TNF- $\alpha$ therapy [132, 135], but others did not show any variation [134] (Table 1). However, all the data presented showed that visfatin participates in RA pathology, even if the exact mechanisms by which this adipokine exerts its proinflammatory and catabolic actions are not completely understood.

At cartilage level, human OA chondrocytes produce visfatin. This adipokine increases the expression of ADAMTS4, ADAMTS5, MMP-3, and MMP-13, which are very relevant cartilage degradative enzymes [136]. Moreover, OA patients had higher synovial fluid visfatin concentrations, which are correlated with degradation biomarkers such as collagen type II and aggrecan [68]. Taken together, these data indicate that visfatin develops catabolic functions at cartilage level and it could play an important role in the pathophysiology of OA.

Studies performed in SLE and AS patients present conflicting results. Some authors determined higher visfatin levels in SLE patients than in healthy controls [114], but others did not found any variation between patients and controls [137]. Similarly, there was no association between visfatin levels and disease activity in both SLE and AS [81, 137].

\section{Resistin}

Resistin is also known as ADSF (adipocyte-secreted factor) or FIZZ3 (found in inflammatory zone 3 ). It is a $12.5 \mathrm{kDa}$ protein that belongs to the resistin-like molecules (RELMs) family [70]. The major source of resistin in mice is white adipose tissue (WAT) [69], whereas, in humans, it is predominantly expressed in macrophages [138]. Thus, in human adipose tissue, resistin is mainly produced by nonadipocyte resident inflammatory cells [139]. Resistin receptor remains unknown, but recently TLR4 was proposed to mediate resistin inflammatory responses in human cells [140]. Serum resistin levels increase with obesity in mice, rats, and humans $[141,142]$. In animal models, resistin promotes insulin resistance, while the evidence for this effect in human is less clear [70,143], so that it was proposed as potential link between obesity and diabetes $[70]$.

7.1. Resistin and Metabolic Syndrome. In humans, data on the role of this adipokine in insulin sensitivity and obesity are controversial [144]. Some authors indicated that increased serum resistin levels are associated with increased obesity, visceral fat [70], insulin resistance, and T2DM, while other groups failed to observe such correlations [145]. Recent 
investigations have attempted to shed light on the debate $[146,147]$. As MetS by itself is associated with inflammation, there might be the possibility that resistin is rather associated with inflammation markers that would appear at different stages of MetS development and its correlation with other metabolic and anthropometric parameters like glucose, blood lipids, and BMI is just a secondary effect [148]. Whether resistin is an active player or merely a responder in metabolic dysfunction cannot be fully determined without understanding the regulation of resistin itself. Genetic determinants of resistin expression may provide additional clues about the role of resistin in human susceptibility to disease [149] (Figure 2).

7.2. Resistin and Rheumatic Diseases. Until now, a significant difference was not found in serum resistin levels between RA patients and healthy controls [57, 150]. However, a role for resistin has been proposed and its involvement in RA pathology was explored [151]. Recombinant resistin increases the production of several proinflammatory cytokines, and the intra-articular injection of this adipokine in the knee joints of mice causes arthritis [151]. In humans, there is also evidence for a role of resistin in RA pathology. Anti-TNF drugs reduced serum resistin levels $[135,152]$ (Table 1), but no association has been found between resistin concentrations and radiographic progression [133]. By contrast, there are several studies that report an association between resistin and markers of inflammation such as C-reactive protein (CRP), erythrocyte sedimentation rate (ESR), IL- 6, IL-1RA, or leukocyte count in RA patients $[56,150,153]$. Furthermore, resistin has been correlated with disease activity and joint destruction [153], and synovial fluid samples from RA patients showed higher levels of this adipokine than those from OA patients [151,153], suggesting that resistin is produced in the inflamed joint.

\section{Other Adipokines}

8.1. Lipocalin-2. Lipocalin-2 (LCN2), also known as siderocalin, 24p3, uterocalin, and neutrophil gelatinase-associated lipocalin (NGAL), is a $25 \mathrm{kDa}$ glycoprotein isolated from neutrophil granules, although WAT is thought to be the main source [154]. This adipokine is believed to bind small lipophilic substances, such as steroids and LPS [155], and has been reported to have roles in the induction of apoptosis in hematopoietic cells [156], transport of fatty acids [71], modulation of inflammation [157], and metabolic homeostasis [158]. LCN2 expression is altered in several pathologic conditions, such as adipose tissue hypoxia and obesity [158, 159]. Nevertheless, whether lipocalin-2 plays a role in the pathogenesis of obesity-related diseases has not been investigated so far.

Recent studies have reported the association between serum LCN2 concentrations and various metabolic parameters and inflammatory markers $[158,160,161]$. The study of Jang et al. provides the first clinical evidence demonstrating that serum concentrations of LCN2 are closely associated with obesity and its related chronic inflammation and metabolic complications. Patients with MetS showed higher levels of LCN2 than those without MetS. However, correlation between serum LCN2 concentration and the number of MetS components was not significant. Nonetheless, they suggest serum LCN2 as a useful biomarker for evaluating the outcomes in various clinical settings of obesity-related metabolic and cardiovascular disease [162].

LCN2 is expressed in different types of cells and it has been identified in chondrocytes [163]. In these cells, LCN2 expression was modulated by IL- $1 \beta$, leptin, adiponectin, LPS, and dexamethasone [164]. In addition, the synovial fluid from patients with knee OA was found to be enriched with MMP-9/LCN2 complexes that have been involved in matrix degradation [165]. Recently, the group of Katano confirmed that synovial fluid levels of LCN2 were significantly higher in patients with RA than in those with OA. Through a proteome analysis, they showed that granulocyte macrophage colony-stimulating factor (GM-CSF) can contribute to the pathogenesis of RA by upregulating LCN2 in neutrophils, followed by the induction of a series of enzymes, such as cathepsin D, transitional endoplasmic reticulum ATPase (TERA), and transglutaminase $2(\operatorname{tg} 2)$ in synoviocytes, which could contribute to the proliferation of synovial cells and infiltration of inflammatory cells inside the synovium [166]. Accordingly, lipocalin may regulate immune cell recruitment to the site of inflammation, a process essential for the controlled initiation, perpetuation, and resolution of inflammatory processes [167]. Finally, very recently, the NEIRID group had showed that nitric oxide boosts TLR- 4 mediated lipocalin expression in chondrocytes, suggesting the existence of a feedback loop regulating the expression of this adipokine [168].

8.2. Chemerin. Chemerin, also known as TIG2 (tazaroteneinduced gene 2) or RARRES2 (retinoic acid receptor responder 2), is an adipokine with chemoattractant activity. It is secreted as an $18 \mathrm{kDa}$ inactive proprotein and it is activated by posttranslational C-terminal cleavage. Chemerin acts via the G-protein-coupled receptor chemokine-like receptor 1 (CMKLR1 or ChemR23) [169]. Chemerin and its receptor are mainly, but not exclusively, expressed in adipose tissue [170] and, for instance, dendritic cells and macrophages express chemerin receptor [171]. It has been implicated in immune [169] and metabolic homeostasis [170]. Chemerin expression correlates with BMI in humans and is upregulated in the adipose tissue of obese and T2DM sand rats (Psammomys obesus) [170]. IL-1 $\beta$ has been reported to induce chemerin expression in mouse adipocytes [172].

Bozaoglu et al. identified, for the first time, chemerin as a novel adipokine, which may play a role in the pathophysiology of obesity and MetS. They showed that plasma chemerin concentrations were strongly associated with BMI, plasma triglycerides, and blood pressure. These findings suggest that chemerin may play an important role in obesity and MetS. Moreover, it raises the possibility that chemerin may be of value as a biomarker for this disorder [108]. Recently, two studies determine chemerin levels in plasma and subcutaneous adipose tissue (SAT) in nascent MetS 
patients, without concomitant diabetes or CVD. In their studies, they made the observation that both plasma and SAT levels of chemerin were higher in subjects with nascent MetS, suggesting an early role of chemerin in the pathogenesis of MetS $[95,173]$.

Interestingly, chondrocytes express chemerin and its receptor $[164,174]$, and IL- $1 \beta$ is able to increase chemerin expression [164]. In the same way, Berg et al. have demonstrated that recombinant chemerin enhances the production of several proinflammatory cytokines (TNF- $\beta \alpha$, IL- $1 \beta$, IL6, and IL-8), as well as different MMPs (MMP-1, MMP2, MMP-3, MMP-8, and MMP-13), in human articular chondrocytes [174]. These factors have a role in the joint inflammation and degradation of the extracellular matrix by causing breakdown of the collagen and aggrecan framework and result in irreversible destruction of the cartilage in OA and RA. Furthermore, chemerin was recently detected in synovial fluid from OA and RA patients $[175,176]$. The serum concentration of this adipokine correlated with disease severity in OA [176] and with disease activity in RA [177].

8.3. Omentin. Omentin is a $40 \mathrm{kDa}$ protein secreted by omental adipose tissue that has previously been identified as intelectin, a new type of $\mathrm{Ca}^{2+}$-dependent lectin. It is highly and selectively expressed in visceral adipose tissue, and that might regulate insulin action by increasing insulin-mediated glucose uptake in human subcutaneous and omental adipocytes [178]. Plasma omentin levels and gene expression in adipose tissue decrease with obesity and correlate positively with plasma adiponectin and high-density lipoprotein levels and negatively with waist circumference, BMI, and insulin levels, all of which are markers of MetS [179]. Expression of the omentin gene was demonstrated in omental adipose tissue of patients with Crohn's disease, suggesting a role in chronic inflammatory diseases [180].

In two different studies, the group of Bremer determined omentin levels in nascent MetS patients. They observed that both plasma and subcutaneous adipose tissue levels of omentin were lower in subjects with nascent MetS, suggesting that lower secretion of omentin from SAT in subjects with nascent MetS establishes the presence of omentin deficiency in the syndrome as well $[95,173]$.

More recently, Šenolt et al. have demonstrated reduced levels of omentin in the synovial fluid of patients with RA compared with those with OA [181]. This finding suggests that this adipokine is likely to be involved in OA pathophysiology.

\section{Conclusions}

The relationships among metabolic syndrome, adipokines, and rheumatic diseases are complex, encompassing a variety of influences that include also cardiovascular function, metabolic status, biomechanics, and also behavioural aspects. A critical aspect that we have always borne in mind is that MetS is closely related to inflammation or chronic "lowgrade inflammatory state" that will influence heavily the courses of rheumatic diseases. Thus, the first line approach to tackle MetS is the prevention of excessive weight gain across lifespan. Of course, this kind of approach should not be an individual task but rather should be a social priority. However, this strategy, in order to be effective, might require deep sociocultural changes, as well as international coordinated social instructions that right now are really far from being achieved.

\section{Conflict of Interests}

The authors declare that there is no conflict of interests regarding the publication of this paper.

\section{Acknowledgments}

The work of Oreste Gualillo is funded by Instituto de Salud Carlos III and Xunta de Galicia (SERGAS) through a research-staff stabilization contract. Oreste Gualillo is supported by Instituto de Salud Carlos III and Xunta de Galicia (Grants PI11/01073 and 10CSA918029PR). This work was also partially supported by the RETICS Programme, RD08/0075 (RIER) via Instituto de Salud Carlos III (ISCIII), within the VI $\mathrm{NP}$ of $\mathrm{R}+\mathrm{D}+\mathrm{I} 2008-2011$ (Oreste Gualillo). Morena Scotece is a recipient of the "FPU" Program of the Spanish Ministry of Education. Javier Conde is a recipient of a fellowship from the Foundation IDIS-Ramón Dominguez. Veronica Lopez is a recipient of a grant from Instituto de Salud Carlos III. Vanessa Abella is a recipient of a predoctoral fellowship from ESF (European Social Fund) grant from Xunta de Galicia through a contract signed with University of Coruña. Veronica Lazzaro is a recipient of a predoctoral fellowship from ESF (European Social Fund), Regione Calabria, Universitá della Magna Grecia, Dipartimento di Scienze della Salute, Catanzaro, Italy.

\section{References}

[1] R. H. Eckel, S. M. Grundy, and P. Z. Zimmet, “The metabolic syndrome," The Lancet, vol. 365, no. 9468, pp. 1415-1428, 2005.

[2] P. I. Sidiropoulos, S. A. Karvounaris, and D. T. Boumpas, "Metabolic syndrome in rheumatic diseases: epidemiology, pathophysiology, and clinical implications," Arthritis Research and Therapy, vol. 10, no. 3, article 207, 2008.

[3] R. H. Eckel, K. G. M. M. Alberti, S. M. Grundy, and P. Z. Zimmet, "The metabolic syndrome," The Lancet, vol. 375, no. 9710, pp. 181-183, 2010.

[4] K. G. Alberti and P. Z. Zimmet, "Definition, diagnosis and classification of diabetes mellitus and its complications-part 1: diagnosis and classification of diabetes mellitus provisional report of a WHO consultation," Diabetic Medicine, vol. 15, no. 7, pp. 539-553, 1998.

[5] National Cholesterol Education Program (NCEP) Expert Panel on Detection, Evaluation, and Treatment of High Blood Cholesterol in Adults (Adult Treatment Panel III), "Third report of the national cholesterol education program (NCEP) expert panel on detection, evaluation, and treatment of high blood cholesterol in adults (adult treatment panel III) final report," Circulation, vol. 106, no. 25, pp. 3143-3421, 2002.

[6] K. G. M. M. Alberti and P. Zimmet, "The metabolic syndromea new worldwide definition," The Lancet, vol. 366, no. 9491, pp. 1059-1062, 2005. 
[7] B. Balkau and M. A. Charles, "Comment on the provisional report from the WHO consultation," Diabetic Medicine, vol. 16, no. 5, pp. 442-443, 1999.

[8] Z. T. Bloomgarden, "American association of clinical endocrinologists (AACE) consensus conference on the insulin resistance syndrome: 25-26 August 2002, Washington, DC," Diabetes Care, vol. 26, no. 4, pp. 1297-1303, 2003.

[9] K. G. M. M. Alberti, R. H. Eckel, S. M. Grundy et al., "Harmonizing the metabolic syndrome: a joint interim statement of the international diabetes federation task force on epidemiology and prevention; national heart, lung, and blood institute; American heart association; world heart federation; international atherosclerosis society; and international association for the study of obesity," Circulation, vol. 120, no. 16, pp. 1640-1645, 2009.

[10] P. N. Tyrrell, J. Beyene, B. M. Feldman, B. W. McCrindle, E. D. Silverman, and T. J. Bradley, "Rheumatic disease and carotid intima-media thickness: a systematic review and metaanalysis," Arteriosclerosis, Thrombosis, and Vascular Biology, vol. 30, no. 5, pp. 1014-1026, 2010.

[11] S. M. Naz and D. P. M. Symmons, "Mortality in established rheumatoid arthritis," Best Practice and Research: Clinical Rheumatology, vol. 21, no. 5, pp. 871-883, 2007.

[12] M. T. Nurmohamed, "Cardiovascular risk in rheumatoid arthritis," Autoimmunity Reviews, vol. 8, no. 8, pp. 663-667, 2009.

[13] A. J. Cameron, E. J. Boyko, R. A. Sicree et al., "Central obesity as a precursor to the metabolic syndrome in the AusDiab study and Mauritius," Obesity, vol. 16, no. 12, pp. 2707-2716, 2008.

[14] F. Lago, R. Gómez, J. Conde, M. Scotece, J. J. Gómez-Reino, and O. Gualillo, "Cardiometabolic comorbidities and rheumatic diseases: focus on the role of fat mass and adipokines," Arthritis Care and Research, vol. 63, no. 8, pp. 1083-1090, 2011.

[15] M. Scotece, J. Conde, R. Gómez et al., "Role of adipokines in atherosclerosis: interferences with cardiovascular complications in rheumatic diseases," Mediators of Inflammation, vol. 2012, Article ID 125458, 14 pages, 2012.

[16] J. Conde, M. Scotece, R. Gómez et al., “Adipokines: biofactors from white adipose tissue. A complex hub among inflammation, metabolism, and immunity," BioFactors, vol. 37, no. 6, pp. 413-420, 2011.

[17] R. Gómez, J. Conde, M. Scotece, J. J. Gómez-Reino, F. Lago, and O. Gualillo, "What's new in our understanding of the role of adipokines in rheumatic diseases?" Nature Reviews Rheumatology, vol. 7, no. 9, pp. 528-536, 2011.

[18] R. M. R. Pereira, J. F. de Carvalho, and E. Bonfá, "Metabolic syndrome in rheumatological diseases," Autoimmunity Reviews, vol. 8, no. 5, pp. 415-419, 2009.

[19] I. Ferraz-Amaro, C. González-Juanatey, R. López-Mejias, L. Riancho-Zarrabeitia, and M. A. González-Gay, "Metabolic syndrome in rheumatoid arthritis," Mediators of Inflammation, vol. 2013, Article ID 710928, 11 pages, 2013.

[20] S. A. Karvounaris, P. I. Sidiropoulos, J. A. Papadakis et al., "Metabolic syndrome is common among middle-to-older aged Mediterranean patients with rheumatoid arthritis and correlates with disease activity: a retrospective, cross-sectional, controlled, study," Annals of the Rheumatic Diseases, vol. 66, no. 1, pp. 28-33, 2007.

[21] C. P. Chung, A. Oeser, J. F. Solus et al., "Prevalence of the metabolic syndrome is increased in rheumatoid arthritis and is associated with coronary atherosclerosis," Atherosclerosis, vol. 196, no. 2, pp. 756-763, 2008.
[22] H.-H. Dao, Q.-T. Do, and J. Sakamoto, "Increased frequency of metabolic syndrome among Vietnamese women with early rheumatoid arthritis: a cross-sectional study," Arthritis Research and Therapy, vol. 12, no. 6, article R218, 2010.

[23] C. S. Crowson, E. Myasoedova, J. M. Davis III et al., "Increased prevalence of metabolic syndrome associated with rheumatoid arthritis in patients without clinical cardiovascular disease," Journal of Rheumatology, vol. 38, no. 1, pp. 29-35, 2011.

[24] X. Houard, M. B. Goldring, and F. Berenbaum, "Homeostatic mechanisms in articular cartilage and role of inflammation in osteoarthritis," Current Rheumatology Reports, vol. 15, no. 11, pp. $375-385,2013$.

[25] F. Guilak, "Biomechanical factors in osteoarthritis," Best Practice and Research: Clinical Rheumatology, vol. 25, no. 6, pp. 815-823, 2011.

[26] M. Sowers, C. A. Karvonen-Gutierrez, R. Palmieri-Smith, J. A. Jacobson, Y. Jiang, and J. A. Ashton-Miller, "Knee osteoarthritis in obese women with cardiometabolic clustering," Arthritis Care and Research, vol. 61, no. 10, pp. 1328-1336, 2009.

[27] C. A. Karvonen-Gutierrez, M. R. Sowers, and S. G. Heeringa, "Sex dimorphism in the association of cardiometabolic characteristics and osteophytes-defined radiographic knee osteoarthritis among obese and non-obese adults: NHANES III," Osteoarthritis and Cartilage, vol. 20, no. 7, pp. 614-621, 2012.

[28] E. Yusuf, R. G. Nelissen, A. Ioan-Facsinay et al., "Association between weight or body mass index and hand osteoarthritis: a systematic review," Annals of the Rheumatic Diseases, vol. 69, no. 4, pp. 761-765, 2010

[29] P. Pottie, N. Presle, B. Terlain, P. Netter, D. Mainard, and F. Berenbaum, "Obesity and osteoarthritis: more complex than predicted!," Annals of the Rheumatic Diseases, vol. 65, no. 11, pp. 1403-1405, 2006.

[30] R. A. Puenpatom and T. W. Victor, "Increased prevalence of metabolic syndrome in individuals with osteoarthritis: an analysis of NHANES III data," Postgraduate Medicine, vol. 121, no. 6, pp. 9-20, 2009.

[31] N. Yoshimura, S. Muraki, H. Oka et al., "Accumulation of metabolic risk factors such as overweight, hypertension, dyslipidaemia, and impaired glucose tolerance raises the risk of occurrence and progression of knee osteoarthritis: a 3-year follow-up of the ROAD study," Osteoarthritis and Cartilage, vol. 20, no. 11, pp. 1217-1226, 2012.

[32] Q. Zhuo, W. Yang, J. Chen, and Y. Wang, "Metabolic syndrome meets osteoarthritis," Nature Reviews Rheumatology, vol. 8, no. 12, pp. 729-737, 2012.

[33] B. Parker, M. B. Urowitz, D. D. Gladman et al., "Clinical associations of the metabolic syndrome in systemic lupus erythematosus: data from an international inception cohort," Annals of the Rheumatic Diseases, vol. 72, no. 8, pp. 1308-1314, 2013.

[34] B. Parker, Y. Ahmad, J. Shelmerdine et al., "An analysis of the metabolic syndrome phenotype in systemic lupus erythematosus," Lupus, vol. 20, no. 14, pp. 1459-1465, 2011.

[35] J. M. Sabio, M. Zamora-Pasadas, J. Jiménez-Jáimez et al., "Metabolic syndrome in patients with systemic lupus erythematosus from Southern Spain," Lupus, vol. 17, no. 9, pp. 849-859, 2008.

[36] C. P. Chung, I. Avalos, A. Oeser et al., "High prevalence of the metabolic syndrome in patients with systemic lupus erythematosus: association with disease characteristics and 
cardiovascular risk factors," Annals of the Rheumatic Diseases, vol. 66, no. 2, pp. 208-214, 2007.

[37] B. Parker and I. Bruce, "SLE and metabolic syndrome," Lupus, vol. 22, no. 12, pp. 1259-1266, 2013.

[38] D. Malesci, A. Niglio, G. A. Mennillo, R. Buono, G. Valentini, and G. La Montagna, "High prevalence of metabolic syndrome in patients with ankylosing spondylitis," Clinical Rheumatology, vol. 26, no. 5, pp. 710-714, 2007.

[39] J. A. Papadakisl, P. I. Sidiropoulos, S. A. Karvounaris et al., "High prevalence of metabolic syndrome and cardiovascular risk factors in men with ankylosing spondylitis on anti-TNF $\alpha$ treatment: correlation with disease activity," Clinical and Experimental Rheumatology, vol. 27, no. 2, pp. 292-298, 2009.

[40] M. Ramos-Casals, P. Brito-Zerón, A. Sisó et al., "High prevalence of serum metabolic alterations in primary Sjögren's syndrome: influence on clinical and immunological expression," Journal of Rheumatology, vol. 34, no. 4, pp. 754-761, 2007.

[41] R. Gomez, F. Lago, J. Gomez-Reino, C. Dieguez, and O. Gualillo, "Adipokines in the skeleton: influence on cartilage function and joint degenerative diseases," Journal of Molecular Endocrinology, vol. 43, no. 1, pp. 11-18, 2009.

[42] F. Lago, C. Dieguez, J. Gómez-Reino, and O. Gualillo, "Adipokines as emerging mediators of immune response and inflammation," Nature Clinical Practice Rheumatology, vol. 3, no. 12, pp. 716-724, 2007.

[43] J. Conde, M. Scotece, V. López et al., "Differential expression of adipokines in infrapatellar fat pad (IPFP) and synovium of osteoarthritis patients and healthy individuals," Annals of the Rheumatic Diseases, 2013.

[44] Y. Deng and P. E. Scherer, "Adipokines as novel biomarkers and regulators of the metabolic syndrome," Annals of the New York Academy of Sciences, vol. 1212, pp. E1-E19, 2010.

[45] S. B. Patel, G. P. Reams, R. M. Spear, R. H. Freeman, and D. Villarreal, "Leptin: linking obesity, the metabolic syndrome, and cardiovascular disease," Current Hypertension Reports, vol. 10, no. 2, pp. 131-137, 2008.

[46] N. Ouchi, J. L. Parker, J. J. Lugus, and K. Walsh, "Adipokines in inflammation and metabolic disease," Nature Reviews Immunology, vol. 11, no. 2, pp. 85-97, 2011.

[47] Y. Zhang, R. Proenca, M. Maffei, M. Barone, L. Leopold, and J. M. Friedman, "Positional cloning of the mouse obese gene and its human homologue," Nature, vol. 372, no. 6505, pp. 425-432, 1994.

[48] O. Gualillo, S. Eiras, F. Lago, C. Diéguez, and F. F. Casanueva, "Elevated serum leptin concentrations induced by experimental acute inflammation," Life Sciences, vol. 67, no. 20, pp. 2433-2441, 2000.

[49] R. S. Ahlma, D. Prabakaran, C. Mantzoros et al., "Role of leptin in the neuroendocrine response to fasting," Nature, vol. 382, no. 6588, pp. 250-252, 1996.

[50] M.-H. Gannagé-Yared, S. Khalife, M. Semaan, F. Fares, S. Jambart, and G. Halaby, "Serum adiponectin and leptin levels in relation to the metabolic syndrome, androgenic profile and somatotropic axis in healthy non-diabetic elderly men," European Journal of Endocrinology, vol. 155, no. 1, pp. 167-176, 2006.

[51] A. Quercioli, F. Montecucco, Z. Pataky et al., "Improvement in coronary circulatory function in morbidly obese individuals after gastric bypass-induced weight loss: relation to alterations in endocannabinoids and adipocytokines," European Heart Journal, vol. 34, no. 27, pp. 2063-2073, 2013.
[52] A. Quercioli, Z. Pataky, F. Montecucco et al., "Coronary vasomotor control in obesity and morbid obesity: contrasting flow responses with endocannabinoids, leptin, and inflammation," JACC: Cardiovascular Imaging, vol. 5, no. 8, pp. 805-815, 2012.

[53] P. W. Franks, S. Brage, J. Luan et al., "Leptin predicts a worsening of the features of the metabolic syndrome independently of obesity," Obesity Research, vol. 13, no. 8, pp. 1476-1484, 2005.

[54] F.-H. Chiu, C. H. Chuang, W. C. Li et al., "The association of leptin and C-reactive protein with the cardiovascular risk factors and metabolic syndrome score in Taiwanese adults," Cardiovascular Diabetology, vol. 11, article 40, 2012.

[55] A. Yadav, P. jyoti, S. K. Jain, and J. Bhattacharjee, "Correlation of adiponectin and leptin with insulin resistance: a pilot study in healthy North Indian population," Indian Journal of Clinical Biochemistry, vol. 26, no. 2, pp. 193-196, 2011.

[56] P. Kontunen, K. Vuolteenaho, R. Nieminen et al., "Resistin is linked to inflammation, and leptin to metabolic syndrome, in women with inflammatory arthritis," Scandinavian Journal of Rheumatology, vol. 40, no. 4, pp. 256-262, 2011.

[57] M. Otero, R. Logo, R. Gomez et al., "Changes in plasma levels of fat-derived hormones adiponectin, leptin, resistin and visfatin in patients with rheumatoid arthritis," Annals of the Rheumatic Diseases, vol. 65, no. 9, pp. 1198-1201, 2006.

[58] R. H. Unger and P. E. Scherer, "Gluttony, sloth and the metabolic syndrome: a roadmap to lipotoxicity," Trends in Endocrinology and Metabolism, vol. 21, no. 6, pp. 345-352, 2010.

[59] S. Takeda and G. Karsenty, "Molecular bases of the sympathetic regulation of bone mass," Bone, vol. 42, no. 5, pp. 837-840, 2008.

[60] M. Otero, J. J. G. Reino, and O. Gualillo, "Synergistic induction of nitric oxide synthase type II: in vitro effect of leptin and interferon- $\gamma$ in human chondrocytes and ATDC 5 chondrogenic cells," Arthritis and Rheumatism, vol. 48, no. 2, pp. 404-409, 2003.

[61] M. A. Gonzalez-Gay, M. T. Garcia-Unzueta, A. Berja et al., "Anti-TNF- $\alpha$ therapy does not modulate leptin in patients with severe rheumatoid arthritis," Clinical and Experimental Rheumatology, vol. 27, no. 2, pp. 222-228, 2009.

[62] S. M. Olama, M. K. Senna, and M. Elarman, "Synovial/serum leptin ratio in rheumatoid arthritis: the association with activity and erosion," Rheumatology International, vol. 32, no. 3, pp. 683-690, 2012.

[63] Y. H. Rho, J. Solus, T. Sokka et al., "Adipocytokines are associated with radiographic joint damage in rheumatoid arthritis," Arthritis and Rheumatism, vol. 60, no. 7, pp. 1906-1914, 2009.

[64] H. Dumond, N. Presle, B. Terlain et al., "Evidence for a key role of leptin in osteoarthritis," Arthritis and Rheumatism, vol. 48, no. 11, pp. 3118-3129, 2003.

[65] C. Procaccini, F. Carbone, M. Galgani et al., "Obesity and susceptibility to autoimmune diseases," Expert Review of Clinical Immunology, vol. 7, no. 3, pp. 287-294, 2011.

[66] C. A. Notley and M. R. Ehrenstein, "The yin and yang of regulatory T cells and inflammation in RA," Nature Reviews Rheumatology, vol. 6, no. 10, pp. 572-577, 2010.

[67] W. Tan, F. Wang, M. Zhang, D. Guo, Q. Zhang, and S. He, "High adiponectin and adiponectin receptor 1 expression in synovial fluids and synovial tissues of patients with rheumatoid arthritis," Seminars in Arthritis and Rheumatism, vol. 38, no. 6, pp. 420427, 2009.

[68] Y. Duan, D. Hao, M. Li et al., "Increased synovial fluid visfatin is positively linked to cartilage degradation biomarkers in osteoarthritis," Rheumatology International, vol. 32, no. 4, pp. 985-990, 2012. 
[69] C. M. Steppan, E. J. Brown, C. M. Wright et al., "A family of tissue-specific resistin-like molecules," Proceedings of the National Academy of Sciences of the United States of America, vol. 98, no. 2, pp. 502-506, 2001.

[70] C. M. Steppan, S. T. Bailey, S. Bhat et al., "The hormone resistin links obesity to diabetes," Nature, vol. 409, no. 6818, pp. 307-312, 2001.

[71] S. T. Chu, H. J. Lin, H. L. Huang, and Y. H. Chen, "The hydrophobic pocket of $24 \mathrm{p} 3$ protein from mouse uterine luminal fluid: fatty acid and retinol binding activity and predicted structural similarity to lipocalins," Journal of Peptide Research, vol. 52, no. 5, pp. 390-397, 1998.

[72] J. H. Ku, C. K. Lee, B. S. Joo et al., "Correlation of synovial fluid leptin concentrations with the severity of osteoarthritis," Clinical Rheumatology, vol. 28, no. 12, pp. 1431-1435, 2009.

[73] T. Simopoulou, K. N. Malizos, D. Iliopoulos et al., "Differential expression of leptin and leptin's receptor isoform (Ob-Rb) mRNA between advanced and minimally affected osteoarthritic cartilage; effect on cartilage metabolism," Osteoarthritis and Cartilage, vol. 15, no. 8, pp. 872-883, 2007.

[74] J. Conde, M. Scotece, V. López et al., "Adiponectin and leptin induce VCAM-1 expression in human and murine chondrocytes," PLoS ONE, vol. 7, no. 12, Article ID e52533, 2012.

[75] R. Gómez, M. Scotece, J. Conde, J. J. Gómez-Reino, F. Lago, and O. Gualillo, "Adiponectin and leptin increase IL-8 production in human chondrocytes," Annals of the Rheumatic Diseases, vol. 70, no. 11, pp. 2052-2054, 2011.

[76] T. M. Griffin, J. L. Huebner, V. B. Kraus, and F. Guilak, "Extreme obesity due to impaired leptin signaling in mice does not cause knee osteoarthritis," Arthritis and Rheumatism, vol. 60, no. 10, pp. 2935-2944, 2009.

[77] K.-E. Sada, Y. Yamasaki, M. Maruyama et al., "Altered levels of adipocytokines in association with insulin resistance in patients with systemic lupus erythematosus," Journal of Rheumatology, vol. 33, no. 8, pp. 1545-1552, 2006.

[78] M. Vadacca, D. Margiotta, A. Rigon et al., "Adipokines and systemic lupus erythematosus: relationship with metabolic syndrome and cardiovascular disease risk factors," Journal of Rheumatology, vol. 36, no. 2, pp. 295-297, 2009.

[79] J. B. de Sanctis, M. Zabaleta, N. E. Bianco, J. V. Garmendia, and L. Rivas, "Serum adipokine levels in patients with systemic lupus erythematosus," Autoimmunity, vol. 42, no. 4, pp. 272274, 2009.

[80] M. Wisłowska, M. Rok, K. Stępień, and A. Kuklo-Kowalska, "Serum leptin in systemic lupus erythematosus," Rheumatology International, vol. 28, no. 5, pp. 467-473, 2008.

[81] H. Hulejová, A. Levitová, M. Kuklová et al., "No effect of physiotherapy on the serum levels of adipocytokines in patients with ankylosing spondylitis," Clinical Rheumatology, vol. 31, no. 1, pp. 67-71, 2012.

[82] É. Toussirot, G. Streit, N. U. Nguyen et al., "Adipose tissue, serum adipokines, and ghrelin in patients with ankylosing spondylitis," Metabolism, vol. 56, no. 10, pp. 1383-1389, 2007.

[83] I. Sari, T. Demir, L. D. Kozaci et al., "Body composition, insulin, and leptin levels in patients with ankylosing spondylitis," Clinical Rheumatology, vol. 26, no. 9, pp. 1427-1432, 2007.

[84] M.-C. Park, S.-W. Lee, S.-T. Choi, Y.-B. Park, and S.-K. Lee, "Serum leptin levels correlate with interleukin-6 levels and disease activity in patients with ankylosing spondylitis," Scandinavian Journal of Rheumatology, vol. 36, no. 2, pp. 101-106, 2007.
[85] T. Kadowaki and T. Yamauchi, "Adiponectin and adiponectin receptors," Endocrine Reviews, vol. 26, no. 3, pp. 439-451, 2005.

[86] D. K. Oh, T. Ciaraldi, and R. R. Henry, "Adiponectin in health and disease," Diabetes, Obesity and Metabolism, vol. 9, no. 3, pp. 282-289, 2007.

[87] W. Zhu, K. K. Y. Cheng, P. M. Vanhoutte, K. S. L. Lam, and A. Xu, "Vascular effects of adiponectin: molecular mechanisms and potential therapeutic intervention," Clinical Science, vol. 114, no. 5-6, pp. 361-374, 2008.

[88] Y. Okamoto, S. Kihara, T. Funahashi, Y. Matsuzawa, and P. Libby, "Adiponectin: a key adipocytokine in metabolic syndrome," Clinical Science, vol. 110, no. 3, pp. 267-278, 2006.

[89] S. Li, H. J. Shin, E. L. Ding, and R. M. van Dam, "Adiponectin levels and risk of type 2 diabetes: a systematic review and metaanalysis," The Journal of the American Medical Association, vol. 302, no. 2, pp. 179-188, 2009.

[90] F. Lago, C. Dieguez, J. Gómez-Reino, and O. Gualillo, “The emerging role of adipokines as mediators of inflammation and immune responses," Cytokine and Growth Factor Reviews, vol. 18, no. 3-4, pp. 313-325, 2007.

[91] C. Weyer, T. Funahashi, S. Tanaka et al., "Hypoadiponectinemia in obesity and type 2 diabetes: close association with insulin resistance and hyperinsulinemia," Journal of Clinical Endocrinology and Metabolism, vol. 86, no. 5, pp. 1930-1935, 2001.

[92] M. Blüher, J. W. Bullen Jr., J. H. Lee et al., "Circulating adiponectin and expression of adiponectin receptors in human skeletal muscle: associations with metabolic parameters and insulin resistance and regulation by physical training," Journal of Clinical Endocrinology and Metabolism, vol. 91, no. 6, pp. 2310-2316, 2006.

[93] M. E. Trujillo and P. E. Scherer, "Adipose tissue-derived factors: impact on health and disease," Endocrine Reviews, vol. 27, no. 7, pp. 762-778, 2006.

[94] Y.-J. Bae, S.-H. Kim, J.-H. Chung et al., "Evaluation of adiposityrelated biomarkers as metabolic syndrome indicators," Clinical Nutrition Research, vol. 2, no. 2, pp. 91-99, 2013.

[95] A. A. Bremer and I. Jialal, "Adipose tissue dysfunction in nascent metabolic syndrome," Journal of Obesity, vol. 2013, Article ID 393192, 8 pages, 2013.

[96] J.-Y. Kim, S. V. Ahn, J.-H. Yoon et al., "Prospective study of serum adiponectin and incident metabolic syndrome: the ARIRANG study," Diabetes Care, vol. 36, no. 6, pp. 1547-1553, 2013.

[97] M. Inoue, M. Yano, M. Yamakado, E. Maehata, and S. Suzuki, "Relationship between the adiponectin-leptin ratio and parameters of insulin resistance in subjects without hyperglycemia," Metabolism, vol. 55, no. 9, pp. 1248-1254, 2006.

[98] K. Kotani and N. Sakane, "Leptin: adiponectin ratio and metabolic syndrome in the general Japanese population," Korean Journal of Laboratory Medicine, vol. 31, no. 3, pp. 162166, 2011.

[99] A. F. G. Cicero, P. Magni, M. Moré et al., "Adipokines and sexual hormones associated with the components of the metabolic syndrome in pharmacologically untreated subjects: data from the Brisighella heart study," International Journal of Endocrinology, vol. 2011, Article ID 724816, 6 pages, 2011.

[100] M. A. Gonzalez-Gay, J. Llorca, M. T. Garcia-Unzueta et al., "High-grade inflammation, circulating adiponectin concentrations and cardiovascular risk factors in severe rheumatoid arthritis," Clinical and Experimental Rheumatology, vol. 26, no. 4, pp. 596-603, 2008. 
[101] R. Lago, R. Gómez, F. Lago, J. Gómez-Reino, and O. Gualillo, "Leptin beyond body weight regulation-current concepts concerning its role in immune function and inflammation," Cellular Immunology, vol. 252, no. 1-2, pp. 139-145, 2008.

[102] K.-M. Tong, C.-P. Chen, K.-C. Huang et al., "Adiponectin increases MMP-3 expression in human chondrocytes through AdipoR1 signaling pathway," Journal of Cellular Biochemistry, vol. 112, no. 5, pp. 1431-1440, 2011.

[103] A. Schäffler, A. Ehling, E. Neumann et al., "Adipocytokines in synovial fluid," The Journal of the American Medical Association, vol. 290, no. 13, pp. 1709-1710, 2003.

[104] M. Ozgen, S. S. Koca, N. Dagli, M. Balin, B. Ustundag, and A. Isik, "Serum adiponectin and vaspin levels in rheumatoid arthritis," Archives of Medical Research, vol. 41, no. 6, pp. 457463, 2010.

[105] H.-M. Choi, Y.-A. Lee, S.-H. Lee et al., "Adiponectin may contribute to synovitis and joint destruction in rheumatoid arthritis by stimulating vascular endothelial growth factor, matrix metalloproteinase-1, and matrix metalloproteinase-13 expression in fibroblast-like synoviocytes more than proinflammatory mediators," Arthritis Research and Therapy, vol. 11, no. 6, article R161, 2009.

[106] K. W. Frommer, A. Schäffler, C. Büchler et al., "Adiponectin isoforms: a potential therapeutic target in rheumatoid arthritis?" Annals of the Rheumatic Diseases, vol. 71, no. 10, pp. 1724-1732, 2012.

[107] T. B. Laurberg, J. Frystyk, T. Ellingsen et al., "Plasma adiponectin in patients with active, early, and chronic rheumatoid arthritis who are steroid- and disease-modifying antirheumatic drug-naive compared with patients with osteoarthritis and controls," Journal of Rheumatology, vol. 36, no. 9, pp. 1885-1891, 2009.

[108] M. Filková, M. Lisková, H. Hulejová et al., "Increased serum adiponectin levels in female patients with erosive compared with non-erosive osteoarthritis," Annals of the Rheumatic Diseases, vol. 68, no. 2, pp. 295-296, 2009.

[109] A. Koskinen, S. Juslin, R. Nieminen, T. Moilanen, K. Vuolteenaho, and E. Moilanen, "Adiponectin associates with markers of cartilage degradation in osteoarthritis and induces production of proinflammatory and catabolic factors through mitogen-activated protein kinase pathways," Arthritis Research and Therapy, vol. 13, no. 6, article R184, 2011.

[110] T.-H. Chen, L. Chen, M.-S. Hsieh, C.-P. Chang, D.-T. Chou, and S.-H. Tsai, "Evidence for a protective role for adiponectin in osteoarthritis," Biochimica et Biophysica Acta, vol. 1762, no. 8, pp. 711-718, 2006.

[111] K. Uchida, K. Urabe, K. Naruse, Z. Ogawa, K. Mabuchi, and M. Itoman, "Hyperlipidemia and hyperinsulinemia in the spontaneous osteoarthritis mouse model, STR/Ort," Experimental Animals, vol. 58, no. 2, pp. 181-187, 2009.

[112] S. Honsawek and M. Chayanupatkul, "Correlation of plasma and synovial fluid adiponectin with knee osteoarthritis severity," Archives of Medical Research, vol. 41, no. 8, pp. 593-598, 2010.

[113] M. Massengale, B. Lu, J. J. Pan, J. N. Katz, and D. H. Solomon, "Adipokine hormones and hand osteoarthritis: radiographic severity and pain," PLoS ONE, vol. 7, no. 10, Article ID e47860, 2012.

[114] C. P. Chung, A. G. Long, J. F. Solus et al., "Adipocytokines in systemic lupus erythematosus: relationship to inflammation, insulin resistance and coronary atherosclerosis," Lupus, vol. 18, no. 9, pp. 799-806, 2009.
[115] M. Al, L. Ng, P. Tyrrell, J. Bargman, T. Bradley, and E. Silverman, "A dipokines as novel biomarkers in paediatric systemic lupus erythematosus," Rheumatology, vol. 48, no. 5, pp. 497-501, 2009.

[116] T. Aprahamian, R. G. Bonegio, C. Richez et al., "The peroxisome proliferator-activated receptor $\gamma$ agonist rosiglitazone ameliorates murine lupus by induction of adiponectin," Journal of Immunology, vol. 182, no. 1, pp. 340-346, 2009.

[117] S. Katsiougiannis, E. K. Kapsogeorgou, M. N. Manoussakis, and F. N. Skopouli, "Salivary gland epithelial cells: a new source of the immunoregulatory hormone adiponectin," Arthritis and Rheumatism, vol. 54, no. 7, pp. 2295-2299, 2006.

[118] S. Katsiougiannis, R. Tenta, and F. N. Skopouli, "Activation of AMP-activated protein kinase by adiponectin rescues salivary gland epithelial cells from spontaneous and interferon- $\gamma$ induced apoptosis," Arthritis and Rheumatism, vol. 62, no. 2, pp. 414-419, 2010.

[119] B. Samal, Y. Sun, G. Stearns, C. Xie, S. Suggs, and I. McNiece, "Cloning and characterization of the cDNA encoding a novel human pre-B-cell colony-enhancing factor," Molecular and Cellular Biology, vol. 14, no. 2, pp. 1431-1437, 1994.

[120] A. Fukuhara, M. Matsuda, M. Nishizawa et al., "Visfatin: a protein secreted by visceral fat that Mimics the effects of insulin," Science, vol. 307, no. 5708, pp. 426-430, 2005.

[121] C. A. Curat, V. Wegner, C. Sengenès et al., "Macrophages in human visceral adipose tissue: increased accumulation in obesity and a source of resistin and visfatin," Diabetologia, vol. 49, no. 4, pp. 744-747, 2006.

[122] V. Catalán, J. Gómez-Ambrosi, A. Rodríguez et al., “Association of increased Visfatin/PBEF/NAMPT circulating concentrations and gene expression levels in peripheral blood cells with lipid metabolism and fatty liver in human morbid obesity," Nutrition, Metabolism and Cardiovascular Diseases, vol. 21, no. 4, pp. 245253, 2011.

[123] D. Friebe, M. Neef, J. Kratzsch et al., "Leucocytes are a major source of circulating nicotinamide phosphoribosyltransferase (NAMPT)/pre-B cell colony (PBEF)/visfatin linking obesity and inflammation in humans," Diabetologia, vol. 54, no. 5, pp. 1200-1211, 2011.

[124] Y.-H. Chang, D.-M. Chang, K.-C. Lin, S.-J. Shin, and Y.-J. Lee, "Visfatin in overweight/obesity, type 2 diabetes mellitus, insulin resistance, metabolic syndrome and cardiovascular diseases: a meta-analysis and systemic review," Diabetes/Metabolism Research and Reviews, vol. 27, no. 6, pp. 515-527, 2011.

[125] D. A. de Luis, R. Aller, M. Gonzalez Sagrado, R. Conde, O. Izaola, and B. de la Fuente, "Serum visfatin levels and metabolic syndrome criteria in obese female subjects," Diabetes/Metabolism Research and Reviews, vol. 29, no. 7, pp. 576581, 2013.

[126] M. Olszanecka-Glinianowicz, P. Kocełak, M. Nylec, J. Chudek, and B. Zahorska-Markiewicz, "Circulating visfatin level and visfatin/insulin ratio in obese women with metabolic syndrome," Archives of Medical Science, vol. 8, no. 2, pp. 214-218, 2012.

[127] M. Olszanecka-Glinianowicz, P. Kocełak, J. Janowska, A. Skorupa, M. Nylec, and B. Zahorska-markiewicz, "Plasma visfatin and tumor necrosis factor-alpha (TNF- $\alpha$ ) levels in metabolic syndrome," Kardiologia Polska, vol. 69, no. 8, pp. 802-807, 2011.

[128] M. A. Nowell, P. J. Richards, C. A. Fielding et al., "Regulation of pre-B cell colony-enhancing factor by STAT-3-dependent interleukin- 6 trans-signaling: implications in the pathogenesis of rheumatoid arthritis," Arthritis and Rheumatism, vol. 54, no. 7, pp. 2084-2095, 2006. 
[129] N. Busso, M. Karababa, M. Nobile et al., "Pharmacological inhibition of nicotinamide phosphoribosyltransferase/visfatin enzymatic activity identifies a new inflammatory pathway linked to NAD," PLoS ONE, vol. 3, no. 5, Article ID e2267, 2008.

[130] J. Jurcovicová, A. Stofková, M. Skurlová, M. Baculíková, S. Zórad, and M. Stancíková, "Alterations in adipocyte glucose transporter GLUT4 and circulating adiponectin and visfatin in rat adjuvant induced arthritis," General Physiology and Biophysics, vol. 29, no. 1, pp. 79-84, 2010.

[131] E. A. M. Alkady, H. M. Ahmed, L. Tag, and M. A. Abdou, "Serum and synovial adiponectin, resistin, and visfatin levels in rheumatoid arthritis patients. Relation to disease activity," Zeitschrift für Rheumatologie, vol. 70, no. 7, pp. 602-608, 2011.

[132] L. Senolt, O. Kryštůfková, H. Hulejová et al., “The level of serum visfatin (PBEF) is associated with total number of $\mathrm{B}$ cells in patients with rheumatoid arthritis and decreases following $B$ cell depletion therapy," Cytokine, vol. 55, no. 1, pp. 116-121, 2011.

[133] I. R. Klein-Wieringa, M. P. M. van der Linden, R. Knevel et al., "Baseline serum adipokine levels predict radiographic progression in early rheumatoid arthritis," Arthritis and Rheumatism, vol. 63, no. 9, pp. 2567-2574, 2011.

[134] M. A. Gonzalez-Gay, T. R. Vazquez-Rodriguez, M. T. GarciaUnzueta et al., "Visfatin is not associated with inflammation or metabolic syndrome in patients with severe rheumatoid arthritis undergoing anti-TNF- $\alpha$ therapy," Clinical and Experimental Rheumatology, vol. 28, no. 1, pp. 56-62, 2010.

[135] R. Klaasen, M. M. J. Herenius, C. A. Wijbrandts et al., "Treatment-specific changes in circulating adipocytokines: a comparison between tumour necrosis factor blockade and glucocorticoid treatment for rheumatoid arthritis," Annals of the Rheumatic Diseases, vol. 71, no. 9, pp. 1510-1516, 2012.

[136] M. Gosset, F. Berenbaum, C. Salvat et al., "Crucial role of visfatin/pre-B cell colony-enhancing factor in matrix degradation and prostaglandin E2 synthesis in chondrocytes: possible influence on osteoarthritis," Arthritis and Rheumatism, vol. 58, no. 5, pp. 1399-1409, 2008.

[137] M. Ozgen, S. S. Koca, K. Aksoy, N. Dagli, B. Ustundag, and A. Isik, "Visfatin levels and intima-media thicknesses in rheumatic diseases," Clinical Rheumatology, vol. 30, no. 6, pp. 757-763, 2011.

[138] L. Patel, A. C. Buckels, I. J. Kinghorn et al., "Resistin is expressed in human macrophages and directly regulated by PPAR $\gamma$ activators," Biochemical and Biophysical Research Communications, vol. 300, no. 2, pp. 472-476, 2003.

[139] J. N. Fain, P. S. Cheema, S. W. Bahouth, and M. L. Hiler, "Resistin release by human adipose tissue explants in primary culture," Biochemical and Biophysical Research Communications, vol. 300, no. 3, pp. 674-678, 2003.

[140] A. Tarkowski, J. Bjersing, A. Shestakov, and M. I. Bokarewa, "Resistin competes with lipopolysaccharide for binding to tolllike receptor 4," Journal of Cellular and Molecular Medicine, vol. 14, no. 6, pp. 1419-1431, 2010.

[141] M. Degawa-Yamauchi, J. E. Bovenkerk, B. E. Juliar et al., "Serum resistin (FIZZ3) protein is increased in obese humans," Journal of Clinical Endocrinology and Metabolism, vol. 88, no. 11, pp. 5452-5455, 2003.

[142] P. G. McTernan, C. L. McTernan, R. Chetty et al., "Increased resistin gene and protein expression in human abdominal adipose tissue," Journal of Clinical Endocrinology and Metabolism, vol. 87, no. 5, pp. 2407-2410, 2002.

[143] L. K. Heilbronn, J. Rood, L. Janderova et al., "Relationship between serum resistin concentrations and insulin resistance in nonobese, obese, and obese diabetic subjects," Journal of Clinical Endocrinology and Metabolism, vol. 89, no. 4, pp. 1844-1848, 2004.

[144] O. Ukkola, "Resistin-a mediator of obesity-associated insulin resistance or an innocent bystander?" European Journal of Endocrinology, vol. 147, no. 5, pp. 571-574, 2002.

[145] M. A. Lazar, "Resistin- and obesity-associated metabolic diseases," Hormone and Metabolic Research, vol. 39, no. 10, pp. 710716, 2007.

[146] M. Y. Gharibeh, G. M. Al Tawallbeh, M. M. Abboud, A. Radaideh, A. A. Alhader, and O. F. Khabour, "Correlation of plasma resistin with obesity and insulin resistance in type 2 diabetic patients," Diabetes and Metabolism, vol. 36, no. 6, pp. 443-449, 2010.

[147] B. H. Chen, Y. Song, E. L. Ding et al., "Circulating levels of resistin and risk of type 2 diabetes in men and women: results from two prospective cohorts," Diabetes Care, vol. 32, no. 2, pp. 329-334, 2009.

[148] G. D. Norata, M. Ongari, K. Garlaschelli, S. Raselli, L. Grigore, and A. L. Catapano, "Plasma resistin levels correlate with determinants of the metabolic syndrome," European Journal of Endocrinology, vol. 156, no. 2, pp. 279-284, 2007.

[149] D. R. Schwartz and M. A. Lazar, "Human resistin: found in translation from mouse to man," Trends in Endocrinology and Metabolism, vol. 22, no. 7, pp. 259-265, 2011.

[150] T. Yoshino, N. Kusunoki, N. Tanaka et al., "Elevated serum levels of resistin, leptin, and adiponectin are associated with c-reactive protein and also other clinical conditions in rheumatoid arthritis," Internal Medicine, vol. 50, no. 4, pp. 269-275, 2011.

[151] M. Bokarewa, I. Nagaev, L. Dahlberg, U. Smith, and A. Tarkowski, "Resistin, an adipokine with potent proinflammatory properties," Journal of Immunology, vol. 174, no. 9, pp. 57895795, 2005.

[152] M. A. Gonzalez-Gay, M. T. Garcia-Unzueta, C. GonzalezJuanatey et al., "Anti-TNF- $\alpha$ therapy modulates resistin in patients with rheumatoid arthritis," Clinical and Experimental Rheumatology, vol. 26, no. 2, pp. 311-316, 2008.

[153] L. Šenolt, D. Housa, Z. Vernerová et al., "Resistin in rheumatoid arthritis synovial tissue, synovial fluid and serum," Annals of the Rheumatic Diseases, vol. 66, no. 4, pp. 458-463, 2007.

[154] S. Triebel, J. Bläser, H. Reinke, and H. Tschesche, "A $25 \mathrm{kDa} \alpha 2-$ microglobulin-related protein is a component of the $125 \mathrm{kDa}$ form of human gelatinase," FEBS Letters, vol. 314, no. 3, pp. 386388, 1992.

[155] D. R. Flower, "The lipocalin protein family: structure and function," Biochemical Journal, vol. 318, no. 1, pp. 1-14, 1996.

[156] L. R. Devireddy, J. G. Teodoro, F. A. Richard, and M. R. Green, "Induction of apoptosis by a secreted lipocalin that is transcriptionally regulated by IL-3 deprivation," Science, vol. 293, no. 5531, pp. 829-834, 2001.

[157] J. B. Cowland and N. Borregaard, "Molecular characterization and pattern of tissue expression of the gene for neutrophil gelatinase-associated lipocalin from humans," Genomics, vol. 45, no. 1, pp. 17-23, 1997.

[158] Q.-W. Yan, Q. Yang, N. Mody et al., "The adipokine lipocalin 2 is regulated by obesity and promotes insulin resistance," Diabetes, vol. 56, no. 10, pp. 2533-2540, 2007.

[159] G. Sommer, S. Weise, S. Kralisch et al., "Lipocalin-2 is induced by interleukin-1 $\beta$ in murine adipocytes in vitro," Journal of Cellular Biochemistry, vol. 106, no. 1, pp. 103-108, 2009. 
[160] Y. Wang, K. S. L. Lam, E. W. Kraegen et al., "Lipocalin-2 is an inflammatory marker closely associated with obesity, insulin resistance, and hyperglycemia in humans," Clinical Chemistry, vol. 53, no. 1, pp. 34-41, 2007.

[161] J. M. Moreno-Navarrete, M. Manco, J. Ibá ez et al., "Metabolic endotoxemia and saturated fat contribute to circulating NGAL concentrations in subjects with insulin resistance," International Journal of Obesity, vol. 34, no. 2, pp. 240-249, 2010.

[162] Y. Jang, J. H. Lee, Y. Wang, and G. Sweeney, "Emerging clinical and experimental evidence for the role of lipocalin-2 in metabolic syndrome," Clinical and Experimental Pharmacology and Physiology, vol. 39, no. 2, pp. 194-199, 2012.

[163] H. C. Owen, S. J. Roberts, S. F. Ahmed, and C. Farquharson, "Dexamethasone-induced expression of the glucocorticoid response gene lipocalin 2 in chondrocytes," The American Journal of Physiology-Endocrinology and Metabolism, vol. 294, no. 6, pp. E1023-E1034, 2008.

[164] J. Conde, R. Gomez, G. Bianco et al., "Expanding the adipokine network in cartilage: identification and regulation of novel factors in human and murine chondrocytes," Annals of the Rheumatic Diseases, vol. 70, no. 3, pp. 551-559, 2011.

[165] K. Gupta, M. Shukla, J. B. Cowland, C. J. Malemud, and T. M. Haqqi, "Neutrophil gelatinase-associated lipocalin is expressed in osteoarthritis and forms a complex with matrix metalloproteinase 9," Arthritis and Rheumatism, vol. 56, no. 10, pp. 3326-3335, 2007.

[166] M. Katano, K. Okamoto, M. Arito et al., "Implication of granulocyte-macrophage colony-stimulating factor induced neutrophil gelatinase-associated lipocalin in pathogenesis of rheumatoid arthritis revealed by proteome analysis," Arthritis Research and Therapy, vol. 11, no. 1, article R3, 2009.

[167] R. Shashidharamurthy, D. Machiah, J. D. Aitken et al., "Differential role of lipocalin 2 during immune complexmediated acute and chronic inflammation in mice," Arthritis and Rheumatism, vol. 65, no. 4, pp. 1064-1073, 2013.

[168] R. Gómez, M. Scotece, J. Conde et al., "Nitric oxide boosts TLR4 mediated lipocalin 2 expression in chondrocytes," Journal of Orthopaedic Research, vol. 31, no. 7, pp. 1046-1052, 2013.

[169] V. Wittamer, J. Franssen, M. Vulcano et al., "Specific recruitment of antigen-presenting cells by chemerin, a novel processed ligand from human inflammatory fluids," Journal of Experimental Medicine, vol. 198, no. 7, pp. 977-985, 2003.

[170] K. Bozaoglu, K. Bolton, J. McMillan et al., "Chemerin is a novel adipokine associated with obesity and metabolic syndrome," Endocrinology, vol. 148, no. 10, pp. 4687-4694, 2007.

[171] S. Luangsay, V. Wittamer, B. Bondue et al., "Mouse ChemR23 is expressed in dendritic cell subsets and macrophages, and mediates an anti-inflammatory activity of chemerin in a lung disease model," Journal of Immunology, vol. 183, no. 10, pp. 6489-6499, 2009.

[172] S. Kralisch, S. Weise, G. Sommer et al., "Interleukin-1ß induces the novel adipokine chemerin in adipocytes in vitro," Regulatory Peptides, vol. 154, no. 1-3, pp. 102-106, 2009.

[173] I. Jialal, S. Devaraj, H. Kaur, B. Adams-Huet, and A. A. Bremer, "Increased chemerin and decreased omentin-1 in both adipose tissue and plasma in nascent metabolic syndrome," Journal of Clinical Endocrinology and Metabolism, vol. 98, no. 3, pp. 514517, 2013.

[174] V. Berg, B. Sveinbjörnsson, S. Bendiksen, J. Brox, K. Meknas, and Y. Figenschau, "Human articular chondrocytes express ChemR23 and chemerin; ChemR23 promotes inflammatory signalling upon binding the ligand chemerin(21-157)," Arthritis Research and Therapy, vol. 12, no. 6, article 228, 2010.

[175] K. Eisinger, S. Bauer, A. Schäffler et al., "Chemerin induces CCL2 and TLR4 in synovial fibroblasts of patients with rheumatoid arthritis and osteoarthritis," Experimental and Molecular Pathology, vol. 92, no. 1, pp. 90-96, 2012.

[176] K. Huang, G. Du, L. Li, H. Liang, and B. Zhang, "Association of chemerin levels in synovial fluid with the severity of knee osteoarthritis," Biomarkers, vol. 17, no. 1, pp. 16-20, 2012.

[177] Y.-J. Ha, E.-J. Kang, J.-S. Song, Y.-B. Park, S.-K. Lee, and S.T. Choi, "Plasma chemerin levels in rheumatoid arthritis are correlated with disease activity rather than obesity," Joint Bone Spine, 2013.

[178] R.-Z. Yang, M.-J. Lee, H. Hu et al., "Identification of omentin as a novel depot-specific adipokine in human adipose tissue: possible role in modulating insulin action," The American Journal of Physiology -Endocrinology and Metabolism, vol. 290, no. 6, pp. E1253-E1261, 2006.

[179] C. M. de Souza Batista, R.-Z. Yang, M.-J. Lee et al., "Omentin plasma levels and gene expression are decreased in obesity," Diabetes, vol. 56, no. 6, pp. 1655-1661, 2007.

[180] A. Schäffler, M. Neumeier, H. Herfarth, A. Fürst, J. Schölmerich, and C. Büchler, "Genomic structure of human omentin, a new adipocytokine expressed in omental adipose tissue," Biochimica et Biophysica Acta, vol. 1732, no. 1-3, pp. 96-102, 2005.

[181] L. Šenolt, M. Polanská, M. Filková et al., "Vaspin and omentin: new adipokines differentially regulated at the site of inflammation in rheumatoid arthritis," Annals of the Rheumatic Diseases, vol. 69, no. 7, pp. 1410-1411, 2010. 


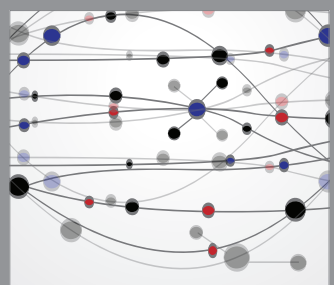

The Scientific World Journal
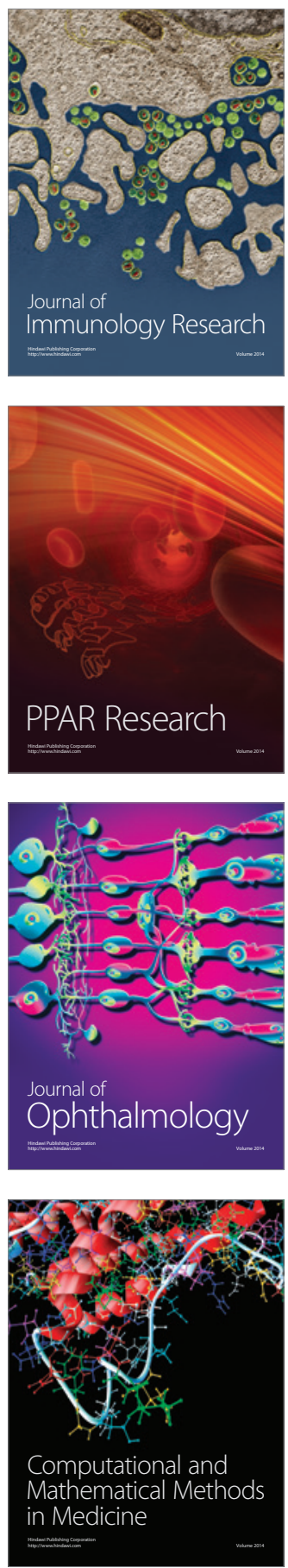

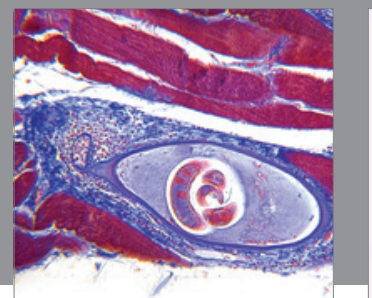

Gastroenterology

Research and Practice
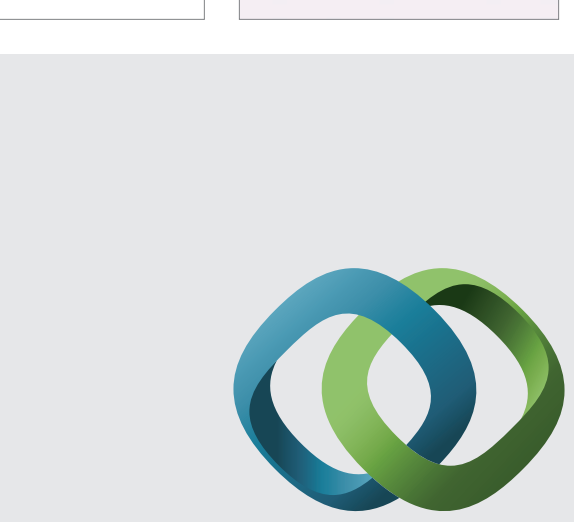

\section{Hindawi}

Submit your manuscripts at

http://www.hindawi.com
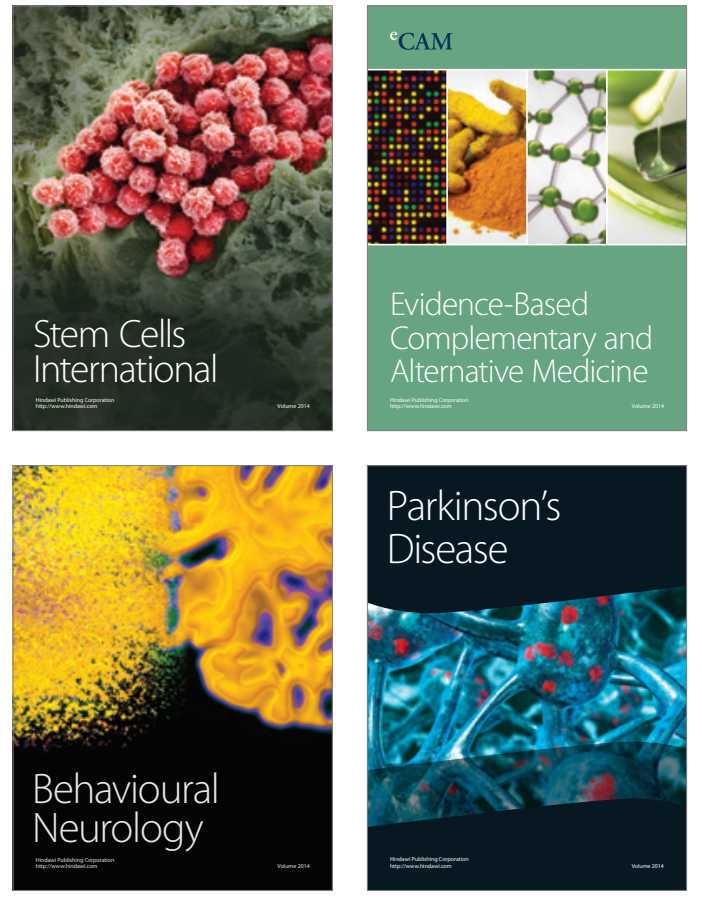
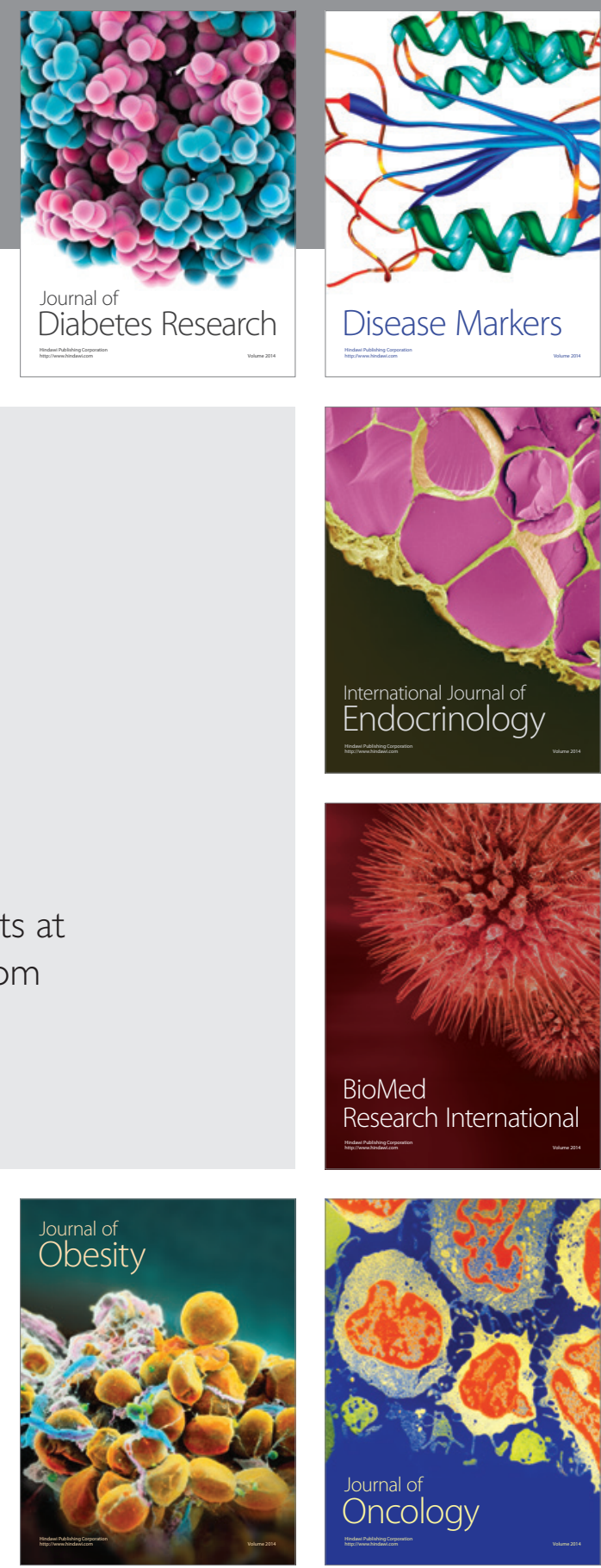

Disease Markers
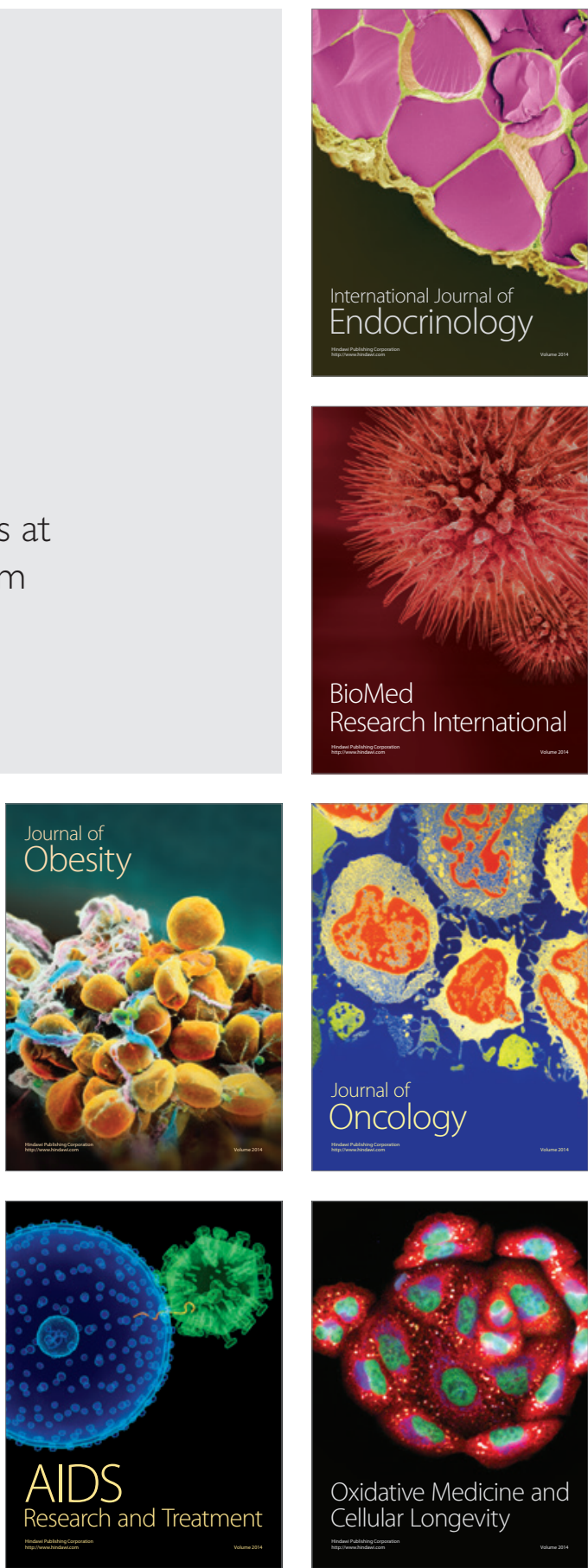